\title{
Synthesis, Crystal Structure, and Hirshfeld Surface Analysis of Ciprofloxacin-Salicylic Acid Molecular Salt
}

\author{
Ravikumar Nagalapalli and Shankar Yaga Bheem \\ Department of Chemistry, BABA Institute of Technology \& Sciences, Visakhapatnam 530048, India \\ Correspondence should be addressed to Ravikumar Nagalapalli; ravikumar.n@bitsvizag.com
}

Received 27 December 2013; Accepted 21 February 2014; Published 7 April 2014

Academic Editor: Mehmet Akkurt

Copyright (c) 2014 R. Nagalapalli and S. Yaga Bheem. This is an open access article distributed under the Creative Commons Attribution License, which permits unrestricted use, distribution, and reproduction in any medium, provided the original work is properly cited.

\begin{abstract}
In the present study, ciprofloxacin-salicylic acid molecular salt has been synthesized and preliminarily characterized by FT-IR spectroscopy. The single crystal X-ray diffraction (SCXRD) reveals the proton transfer from carboxylic acid group of salicylic acid to piperazine moiety in ciprofloxacin confirming the formation of new molecular salt. The molecular packing of the molecular salt is mainly supported by $\mathrm{N}^{+}-\mathrm{H} \cdots \mathrm{O}^{-}, \mathrm{O}-\mathrm{H} \cdots \mathrm{O}, \mathrm{C}-\mathrm{H} \cdots \mathrm{F}, \mathrm{C}-\mathrm{H} \cdots \pi$, and $\pi-\pi$ interactions. The 3D Hirshfeld surfaces and the associated $2 \mathrm{D}$ fingerprint plots were investigated for intermolecular hydrogen bonding interactions.
\end{abstract}

\section{Introduction}

In the pharmaceutical industry salt formation is a widely used method to modulate the physicochemical properties of active pharmaceutical ingredients (APIs) [1]. Salts have been shown to modulate the solubility and bioavailability of APIs [2-4]. An active pharmaceutical salt is a combination of an API with the GRAS (generally regarded as safe by US FDA) listed coformer [5]. A crystal engineering approach in the selection of acid or base for a given drug molecule to make salts or cocrystals is reported in the literature $[6,7]$. Hydrochloride salts are the most preferred method to improve the solubility and stability of APIs [1], but hygroscopicity is a drawback for the hydrochloride salts [8]. Ciprofloxacin (CPF) is a synthetic antibacterial fluoroquinolone related to nalidixic acid having a fluorine atom and piperazine ring at the positions 6 and 7 of quinolone-3-carboxylic acid. It is one of the most active fluoroquinolones with a wide spectrum of biological activity, which is active against both Gram-positive [9] and Gram-negative bacteria [10]. In recent years, CPF has drawn great interest from crystal engineers, due to its tendency to form robust supramolecular architectures with compounds having carboxylic acid functional groups, and also various salts of ciprofloxacin are reported in [11-16]. Our endeavours in the present study are synthesis of CPF molecular salt with GRAS listed salicylic acid, determination of crystal structure by SCXRD, and investigation of various intra- and intermolecular hydrogen bonding by Hirshfeld surface analysis. The molecular structures of CPF and SA are shown in Figure 1.

\section{Materials and Methods}

2.1. Materials. Ciprofloxacin (purity 98\%) and salicylic acid (purity 99\%) were purchased from Alfa Aesar, India. Methanol with HPLC grade purity was obtained from Rankem,, India, and used without further purification. Distilled water was used for crystallization.

2.2. Synthesis of CPF-SA Molecular Salt. A 1:1 stoichiometric ratio of CPF (33 mg, $0.1 \mathrm{mmol}$ ) and SA (13.8 $\mathrm{mg}, 0.1 \mathrm{mmol})$ was dissolved in methanol $(5 \mathrm{~mL})$ and water $(5 \mathrm{~mL})$ mixture at $60^{\circ} \mathrm{C}$ for 10 minutes, and the resulting solution is filtered, cooled, and left for slow evaporation at room temperature. Colorless prism shape crystals of CPF-SA salt, suitable for single crystal X-ray analysis, were obtained after 2 days.

2.3. Infrared Spectroscopy (FT-IR). A Bruker Alpha-T Fourier transform infrared spectrophotometer in the spectral range 4000 to $600 \mathrm{~cm}^{-1}$ with resolution of $2 \mathrm{~cm}^{-1}$ was used to 
<smiles>O=C(O)c1cn(C2CC2)c2cc(N3CCNCC3)c(F)cc2c1=O</smiles>

(a)<smiles>O=C(O)c1ccccc1O</smiles>

(b)
Figure 1: Chemical diagrams of ciprofloxacin (a) and salicylic acid (b).

record the infrared spectra of the samples with the KBr pellet making technique.

2.4. Single Crystal X-Ray Diffraction (SCXRD). Single crystal X-ray diffraction data was collected at 298 (1) K on Rigaku Mercury diffractometer using a single wavelength Enhance $\mathrm{X}$-ray source with Mo $K_{\alpha}$ radiation $(\lambda=0.71070 \AA)$. The Crystal Clear [17] program was used for data collection and cell refinement. The Crystal Structure [17] program was used for data reduction. The structure was solved by SIR92 [18] program and CRYSTALS [19] program was used for structure refinement. The ORTEP [20] program was used for molecular graphics. All the $\mathrm{H}$ positions bound to $\mathrm{C}$ atoms were calculated after each cycle of refinement using a riding model $\mathrm{C}-\mathrm{H}=0.95 \AA$ and $U_{\text {iso }}(\mathrm{H})=1.2 U_{\text {eq }}(\mathrm{C})$. All the $\mathrm{H}$ atoms bound to $\mathrm{N}$ and $\mathrm{O}$ atoms were located in different Fourier maps and freely refined. The crystallographic details were summarized in Table 1.

2.5. Theoretical Calculation. Molecular Hirshfeld surfaces are generated by CrystalExplorer [21] computer program.

\section{Results and Discussion}

The CPF-SA molecular salt crystallizes in triclinic space group $P$-1. The crystal structure of CPF-SA molecular salt has one ciprofloxacin cation, one salicylate, and one-half $\mathrm{O}_{2}$ (Figure 2). The carboxylic acid group of $\mathrm{CPF}$ is in unionized state because the $\mathrm{C}-\mathrm{O}$ and $\mathrm{C}=\mathrm{O}$ bond distances differ by greater than $0.1 \AA$ and are involved in intramolecular hydrogen bonding with the quinolone carbonyl oxygen atom. The carboxylate moiety $\mathrm{C}-\mathrm{O}$ bond distances are about near equal (difference $<0.03 \AA$ ). The carboxylic acid group in $\mathrm{CPF}$ is planar to the quinolone ring, as evidenced by the torsion angle $\left(\mathrm{C} 5-\mathrm{C} 6-\mathrm{C} 10-\mathrm{O} 1=175.8^{\circ}\right)$. A carboxylic acid group in salicylic acid transfers proton to the nitrogen atom of the piperazine moiety in CPF, thereby forming a salicylate anion and CPF cation. Proton transfer is evidenced by the difference between the $\mathrm{C}-\mathrm{O}$ bond distances $\mathrm{C}(18)-\mathrm{O}(5)=$ $1.264(2) \AA$ and $\mathrm{C}(18)-\mathrm{O}(4)=1.249(2) \AA$ of the carboxylate group in salicylate moiety with the $\Delta \mathrm{D}_{\mathrm{C}-\mathrm{O}}$ value of $0.015 \AA$. The relatively small $\Delta \mathrm{D}_{\mathrm{C}-\mathrm{O}}$ value confirmed the formation of carboxylate group [22]. The piperazinium moiety in CPF adopts chair conformation. The CPF aromatic molecular core is $\pi$-stacked infinitely along the crystallographic $b$-axis at
TABLE 1: The crystal and experimental data.

\begin{tabular}{|c|c|}
\hline Empirical formula & $\mathrm{C}_{24} \mathrm{H}_{24} \mathrm{FN}_{3} \mathrm{O}_{7}$ \\
\hline Formula weight & 485.46 \\
\hline Crystal system & Triclinic \\
\hline Space group & $P-1$ \\
\hline$T(\mathrm{~K})$ & $298(1)$ \\
\hline$\lambda(\AA)$ & 0.71070 \\
\hline$a(\AA)$ & $6.9532(10)$ \\
\hline$b(\AA)$ & $9.8979(11)$ \\
\hline$c(\AA)$ & $17.212(2)$ \\
\hline$\alpha\left({ }^{\circ}\right)$ & 79.397(19) \\
\hline$\beta\left(^{\circ}\right)$ & $85.53(2)$ \\
\hline$\gamma\left({ }^{\circ}\right)$ & $83.09(2)$ \\
\hline$V\left(\AA^{3}\right)$ & $1154.0(3)$ \\
\hline$Z$ & 2 \\
\hline$D_{\text {cal }}\left(\mathrm{g} \mathrm{cm}^{-3}\right)$ & 1.397 \\
\hline$\mu\left(\mathrm{mm}^{-1}\right)$ & 0.109 \\
\hline$F\left(\begin{array}{lll}0 & 0 & 0\end{array}\right)$ & 508 \\
\hline Crystal size (mm) & $0.20 \times 0.20 \times 0.20$ \\
\hline Crystal shape and color & Prism, colorless \\
\hline$\theta_{\text {range }}\left({ }^{\circ}\right)$ & 2.4 to 27.4 \\
\hline$h$ & $-8 \rightarrow 7$ \\
\hline$k$ & $-12 \rightarrow 12$ \\
\hline$l$ & $-21 \rightarrow 21$ \\
\hline Reflections collected & 4623 \\
\hline Reflections unique & $4575 / R_{\mathrm{int}}=0.039$ \\
\hline Absorption correction & Multi-scan \\
\hline Goodness-of-fit on $F^{2}$ & 1.18 \\
\hline$R_{1}$ and $w R_{2}$ indices (all data) & $0.055,0.057$ \\
\hline$\Delta \rho_{\max }, \Delta \rho_{\min }\left(\mathrm{e} \cdot \AA^{-3}\right)$ & 0.26 and -0.29 \\
\hline CCDC & 968489 \\
\hline
\end{tabular}

$3.58 \AA$ distance. The CPF cations reside in the $a b$-plane and the salicylate anions are perpendicular to it (along the $c$ axis). The molecular packing of the crystal is also stabilized by $\mathrm{C}-\mathrm{H} \cdots \mathrm{F}$ interactions. The overall crystal packing of the molecular salt is shown in Figure 3. Selected bond lengths, bond angles, torsion angles, and possible hydrogen bonding interactions are given in Table 2.

FT-IR spectroscopy is a widely used technique in the characterization of the formation of new solid phases. The infrared peaks of the $-\mathrm{COOH}$ group of $\mathrm{CPF}$ resonate at 1696 and $1262 \mathrm{~cm}^{-1}$ due to $\mathrm{C}=\mathrm{O}$ and $\mathrm{C}-\mathrm{O}$ stretch, respectively. The broad peak at $2424 \mathrm{~cm}^{-1}$ is attributed to the protonated piperazine nitrogen atom $\left(\mathrm{NH}_{2}{ }^{+}\right)$[23]. Moreover, the appearance of two characteristic carboxylate IR absorption vibrations at 1574 and $1337 \mathrm{~cm}^{-1}$ due to asymmetric and symmetric O-C$\mathrm{O}$ stretch, respectively, confirmed the proton transfer from the $-\mathrm{COOH}$ group in SA.

The 3D Hirshfeld surfaces and 2D fingerprint maps are unique for each molecule in the asymmetric unit of a given crystal. Hirshfeld surfaces provide a three-dimensional picture of intermolecular interactions in a crystal [24]. For CPF-SA molecular salt, $\mathrm{N}-\mathrm{H} \cdots \mathrm{O}$ and $\mathrm{O}-\mathrm{H} \cdots \mathrm{O}$ hydrogen 


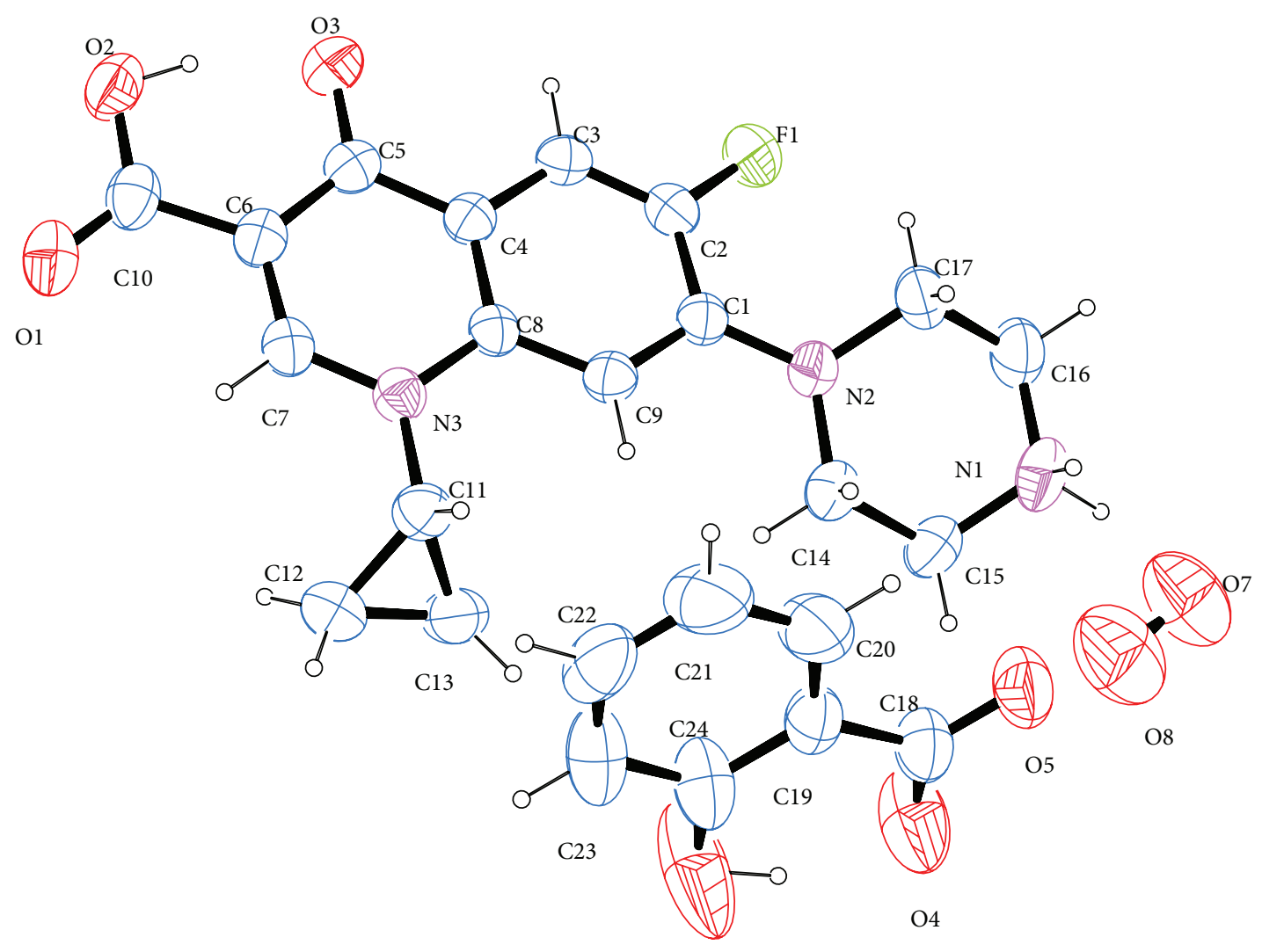

O6

FIGURE 2: ORTEP diagram of CPF-SA molecular salt, showing 50\% probability ellipsoids.

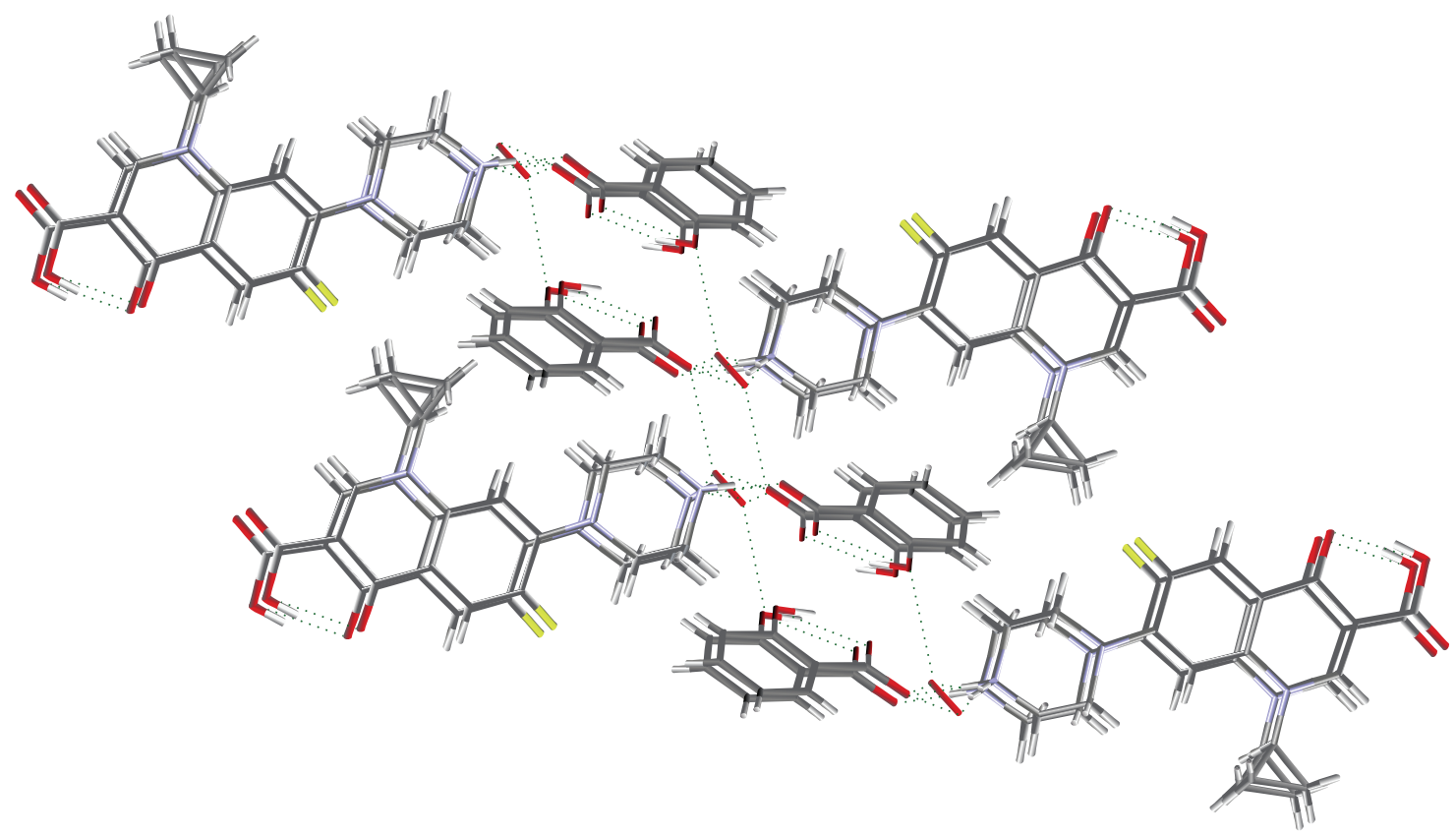

FIGURE 3: Crystal packing diagram of CPF-SA molecular salt. 
TABLE 2: Geometrical parameters.

(a) Selected bond lengths $(\AA)$, bond angles $\left({ }^{\circ}\right)$, and torsion angles $\left(^{\circ}\right)$

\begin{tabular}{lccc}
\hline F1-C2 & $1.3619(13)$ & N1-C16 & $1.488(2)$ \\
O1-C10 & $1.215(2)$ & N1-C15 & $1.483(2)$ \\
O2-C10 & $1.3318(19)$ & N2-C1 & $1.3857(16)$ \\
O3-C5 & $1.2635(16)$ & N2-C14 & $1.4645(18)$ \\
O4-C18 & $1.249(2)$ & N2-C17 & $1.4786(19)$ \\
O5-C18 & $1.264(2)$ & N3-C11 & $1.4589(17)$ \\
O6-C24 & $1.346(2)$ & N3-C7 & $1.3484(17)$ \\
O7-O8 & $1.045(4)$ & N3-C8 & $1.4085(16)$ \\
\hline C15-N1-C16 & $110.77(11)$ & N3-C8-C9 & $120.21(11)$ \\
C14-N2-C17 & $111.31(11)$ & O2-C10-C6 & $115.56(13)$ \\
C1-N2-C14 & $118.30(11)$ & O1-C10-C6 & $123.16(13)$ \\
C1-N2-C17 & $120.91(11)$ & O1-C10-O2 & $121.28(13)$ \\
C7-N3-C11 & $120.32(11)$ & N3-C11-C13 & $118.98(12)$ \\
C7-N3-C8 & $119.30(11)$ & N3-C11-C12 & $118.65(12)$ \\
C8-N3-C11 & $120.29(10)$ & N2-C14-C15 & $111.16(12)$ \\
N2-C1-C9 & $122.20(12)$ & N1-C15-C14 & $111.17(12)$ \\
N2-C1-C2 & $121.91(12)$ & N1-C16-C17 & $109.93(13)$ \\
F1-C2-C1 & $119.16(11)$ & N2-C17-C16 & $109.68(12)$ \\
F1-C2-C3 & $117.41(12)$ & O4-C18-C19 & $118.77(15)$ \\
O3-C5-C4 & $121.59(12)$ & O5-C18-C19 & $119.49(13)$ \\
O3-C5-C6 & $123.06(12)$ & O4-C18-O5 & $121.72(16)$ \\
N3-C7-C6 & $124.37(13)$ & O6-C24-C23 & $118.18(18)$ \\
N3-C8-C4 & $118.97(11)$ & O6-C24-C19 & $121.39(17)$ \\
\hline C1-N2-C14-C15 & $157.17(12)$ & C7-N3-C8-C9 & $178.24(11)$ \\
C10-C6-C7-N3 & $179.51(12)$ & N3-C8-C9-C1 & $176.34(11)$ \\
\hline & & &
\end{tabular}

(b) Hydrogen bonding interactions

\begin{tabular}{lcccc}
\hline Interaction & $\mathrm{D}-\mathrm{H} / \AA$ & $\mathrm{H} \cdots \mathrm{A} / \AA$ & $\mathrm{D} \cdots \mathrm{A} / \AA$ & $\left\langle\mathrm{D}-\mathrm{H} \cdots \mathrm{A} /^{\circ}\right.$ \\
\hline $\mathrm{O} 6-\mathrm{H} 60 \cdots \mathrm{O} 4$ & $0.96(2)$ & $1.64(2)$ & $2.357(3)$ & $152.5(19)$ \\
$\mathrm{N} 1-\mathrm{H} 100 \cdots \mathrm{O} 4^{\mathrm{i}}$ & $0.976(14)$ & $2.473(15)$ & $3.105(2)$ & $122.2(11)$ \\
$\mathrm{N} 1-\mathrm{H} 100 \cdots 5^{\mathrm{i}}$ & $0.976(14)$ & $1.755(14)$ & $2.722(18)$ & $170.8(13)$ \\
$\mathrm{N} 1-\mathrm{H} 101 \cdots \mathrm{O}^{\text {ii }}$ & $0.943(15)$ & $1.873(15)$ & $2.803(3)$ & $168.1(15)$ \\
$\mathrm{N} 1-\mathrm{H} 101 \cdots \mathrm{O} 8^{\mathrm{ii}}$ & $0.943(15)$ & $1.849(15)$ & $2.740(3)$ & $156.5(15)$ \\
$\mathrm{O} 2-\mathrm{H} 201 \cdots \mathrm{O} 3$ & 0.93 & $1.67(2)$ & $2.562(16)$ & $161.6(19)$ \\
$\mathrm{C} 7-\mathrm{H} 7 \cdots \mathrm{O} 1$ & 0.95 & 2.480 & $2.811(18)$ & 101.0 \\
$\mathrm{C} 12-\mathrm{H} 121 \cdots \mathrm{O} 1^{\text {iii }}$ & 0.95 & 2.530 & $3.479(2)$ & 174.0 \\
$\mathrm{C} 15-\mathrm{H} 121 \cdots \mathrm{O} 2^{\text {iv }}$ & 0.95 & 2.590 & $3.395(18)$ & 143.0 \\
$\mathrm{C} 16-\mathrm{H} 162 \cdots \mathrm{O} 6^{\mathrm{v}}$ & 0.95 & 2.490 & $3.371(2)$ & 154.0 \\
$\mathrm{C} 17-\mathrm{H} 171 \cdots \mathrm{F} 1$ & 0.95 & 2.170 & $2.862(2)$ & 129.0 \\
\hline
\end{tabular}

Symmetry codes: (i) $-x+2,-y+1,-z+1$ (ii) $-x+1,-y+1,-z+1$ (iii) $-x+1,-y+2,-z+2$ (iv) $-x+2,-y+1,-z+2$ (v) $x, y-1, z$.

bonding intermolecular interactions appear as two small spikes (upper left spike is sharp and lower right spike is broad) in the $2 \mathrm{D}$ fingerprint map, which have the most significant contribution to the total Hirshfeld surfaces of 1, comprised of $36.6 \%$. The $\mathrm{H}-\mathrm{H}$ interactions, which appeared in the middle of scattered points in the 2D fingerprint map, are comprised of $34.0 \%$ of the total Hirshfeld surfaces. The C-H...F interactions also have a relatively significant contribution to the

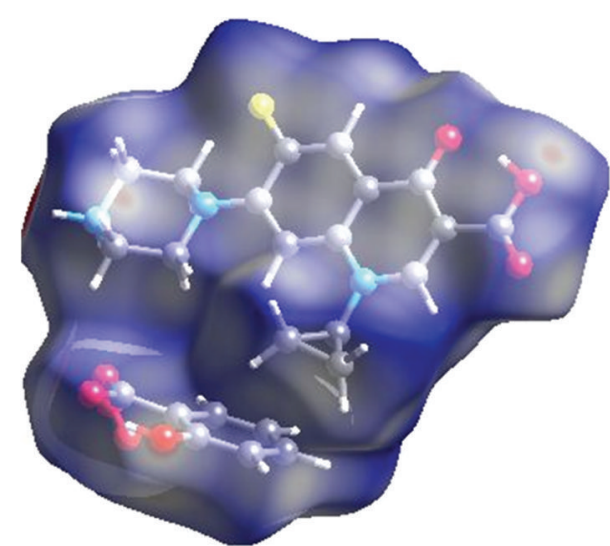

(a)

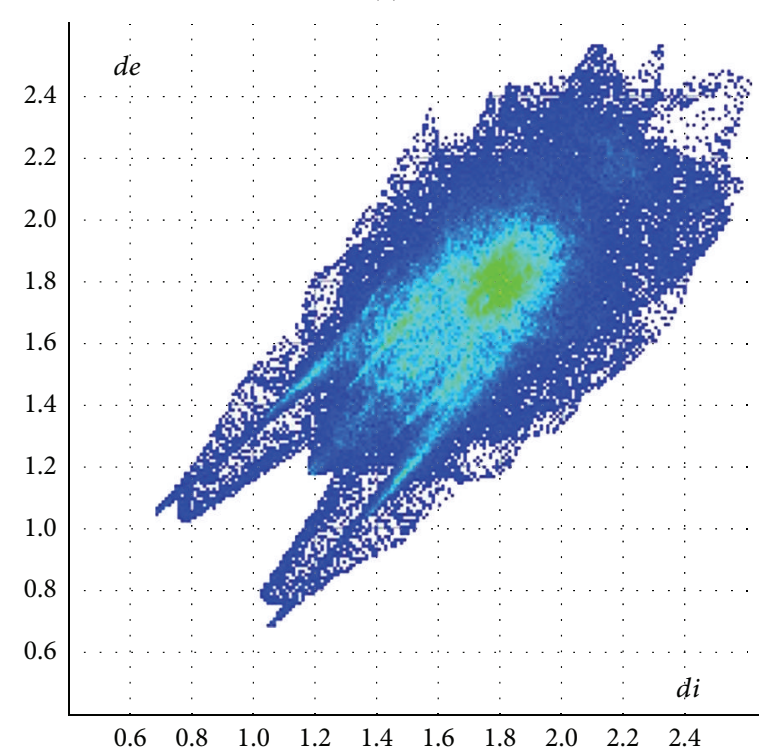

(b)

FIgURE 4: Hirshfeld surface (a) and 2D fingerprint map (b).

total Hirshfeld surfaces of CPF-SA molecular salt, comprised of $6.0 \%$. Apart from those above interactions, the other $\pi \cdots \pi$ $(\mathrm{C}-\mathrm{C})$, lone-pair $\cdots \pi(\mathrm{O}-\mathrm{C})$, and lone-pair $\cdots$ lone-pair $(\mathrm{O}-$ O) interactions are also observed. The 3D Hirshfeld surfaces and 2D fingerprint maps of CPF-SA molecular salt are shown in Figure 4.

\section{Conclusions}

To summarize, we have reported synthesis, X-ray crystal structure analysis, and the Hirshfeld surfaces analyses of ciprofloxacin-salicylic acid molecular salt. The formation of the molecular salt was further characterized and confirmed by FT-IR analysis. The crystal structure of the salt is mainly stabilized by $\mathrm{N}^{+}-\mathrm{H} \cdots \mathrm{O}^{-}, \mathrm{O}-\mathrm{H} \cdots \mathrm{O}, \mathrm{C}-\mathrm{H} \cdots \mathrm{F}$, and $\pi-\pi$ interactions. The 3D Hirshfeld surface analysis and 2D fingerprint maps analysis revealed that $\mathrm{N}-\mathrm{H} \cdots \mathrm{O}$ and $\mathrm{O}-$ $\mathrm{H} \cdots \mathrm{O}$ hydrogen bonding intermolecular interactions are more prominent in the salt. 


\section{Conflict of Interests}

The authors declare that there is no conflict of interests regarding the publication of this paper.

\section{Acknowledgments}

The authors sincerely thank the Management, BITS Vizag, for their financial support and encouragement.

\section{References}

[1] M. Pudipeddi, A. T. M. Serajuddin, D. J. W. Grant, and P. H. Stahl, "Solubility and dissolution of weak acids, bases, and salts", in Handbook of Pharmaceutical Salts, Properties, Selection and Use, P. H. Stahl and C. G. Wermuth, Eds., pp. 19-40, WileyVCH, Weinheim, Germany, 1st edition, 2002.

[2] S. L. Childs, L. J. Chyall, J. T. Dunlap, V. N. Smolenskaya, B. C. Stahly, and G. P. Stahly, "Crystal engineering approach to forming cocrystals of amine hydrochlorides with organic acids. Molecular complexes of fluoxetine hydrochloride with benzoic, succinic, and fumaric acids," Journal of the American Chemical Society, vol. 126, no. 41, pp. 13335-13342, 2004.

[3] S. N. Black, E. A. Collier, R. J. Davey, and R. J. Roberts, "Structure, solubility, screening, and synthesis of molecular salts," Journal of Pharmaceutical Sciences, vol. 96, no. 5, pp. 10531068, 2007.

[4] R. Banerjee, P. M. Bhatt, N. V. Ravindra, and G. R. Desiraju, "Saccharin salts of active pharmaceutical ingredients, their crystal structures, and increased water solubilities," Crystal Growth and Design, vol. 5, no. 6, pp. 2299-2309, 2005.

[5] G. Patrick Stahly, "A survey of cocrystals reported prior to 2000," Crystal Growth and Design, vol. 9, no. 10, pp. 4212-4229, 2009.

[6] Ö. Almarsson and M. J. Zaworotko, "Crystal engineering of the composition of pharmaceutical phases. Do pharmaceutical co-crystals represent a new path to improved medicines?" Chemical Communications, vol. 10, no. 17, pp. 1889-1896, 2004.

[7] N. Blagden, M. de Matas, P. T. Gavan, and P. York, "Crystal engineering of active pharmaceutical ingredients to improve solubility and dissolution rates," Advanced Drug Delivery Reviews, vol. 59, no. 7, pp. 617-630, 2007.

[8] S. M. Berge, L. D. Bighley, and D. C. Monkhouse, "Pharmaceutical salts," Journal of Pharmaceutical Sciences, vol. 66, no. 1, pp. $1-19,1977$.

[9] F. H. Kayser and J. Novak, "In vitro activity of ciprofloxacin against gram-positive bacteria. An overview," American Journal of Medicine, vol. 82, no. 4 A, pp. 33-39, 1987.

[10] J. E. Rudin, C. W. Norden, and E. M. Shinners, "In vitro activity of ciprofloxacin against aerobic gram-negative bacteria," Antimicrobial Agents and Chemotherapy, vol. 26, no. 4, pp. 597598, 1984.

[11] J. S. Reddy, S. V. Ganesh, R. Nagalapalli et al., "Fluoroquinolone salts with carboxylic acids," Journal of Pharmaceutical Sciences, vol. 100, no. 8, pp. 3160-3176, 2011.

[12] I. Turel and A. Golobič, "Crystal structure of ciprofloxacin hydrochloride 1.34-hydrate," Analytical Sciences, vol. 19, no. 2, pp. 329-330, 2003.

[13] B. Lou, D. Boström, and S. P. Velaga, "Monohydrous dihydrogen phosphate salts of norfloxacin and ciprofloxacin," Acta Crystallographica Section C: Crystal Structure Communications, vol. 63, no. 12, pp. o731-o733, 2007.
[14] M. D. Prasanna and T. N. Guru Row, "Hydrogen bonded networks in hydrophilic channels: crystal structure of hydrated ciprofloxacin lactate and comparison with structurally similar compounds," Journal of Molecular Structure, vol. 559, no. 1-3, pp. 255-261, 2001.

[15] X. Li, Y. Hu, Y. Gao, G. G. Z. Zhang, and R. F. Henry, "A methanol hemisolvate of ciprofloxacin," Acta Crystallographica Section E: Structure Reports Online, vol. 62, no. 12, pp. o580305805, 2006.

[16] I. Turel, P. Bukovec, and M. Quirós, "Crystal structure of ciprofloxacin hexahydrate and its characterization," International Journal of Pharmaceutics, vol. 152, no. 1, pp. 59-65, 1997.

[17] Rigaku/MSC and Rigaku Corporation, CrystalClear (Version SM-1. 4. 0 B2) and CrystalStructure (Version 3. 8). Single Crystal Structure Analysis Software, Rigaku/MSC, Tokyo, Japan, 2006.

[18] A. Altomare, G. Cascarano, C. Giacovazzo et al., "SIR92-a program for automatic solution of crystal structures by direct methods," Journal of Applied Crystallography, vol. 27, no. 3, p. 435, 1994.

[19] P. W. Betteridge, J. R. Carruthers, R. I. Cooper, K. Prout, and D. J. Watkin, "CRYSTALS version 12: software for guided crystal structure analysis ," Journal of Applied Crystallography, vol. 36, p. 1487, 2003.

[20] P. McArdle, "ORTEX - an interactive version of ORTEP for use on a PC," Journal of Applied Crystallography, vol. 26, p. 752, 1993.

[21] S. K. Wolff, D. J. Grimwood, J. J. McKinnon, D. Jayatilaka, and M. A. Spackman, CrystalExplorer, Version 1. 5, University of Western Australia, Perth, Australia, 2007.

[22] R. Chada, A. Saini, S. Khullar, D. S. Jain, S. K. Mandal, and T. N. Guru Row, "Crystal structures and physicochemical properties of four new lamotrigine multicomponent forms," Crystal Growth and Design, vol. 13, pp. 858-870, 2013.

[23] S. Basavoju, D. Boström, and S. P. Velaga, "Pharmaceutical cocrystal and salts of norfloxacin," Crystal Growth and Design, vol. 6, no. 12, pp. 2699-2708, 2006.

[24] M. A. Spackman and J. J. McKinnon, "Fingerprinting intermolecular interactions in molecular crystals ," CrystEngComm, vol. 4, pp. 378-392, 2002. 

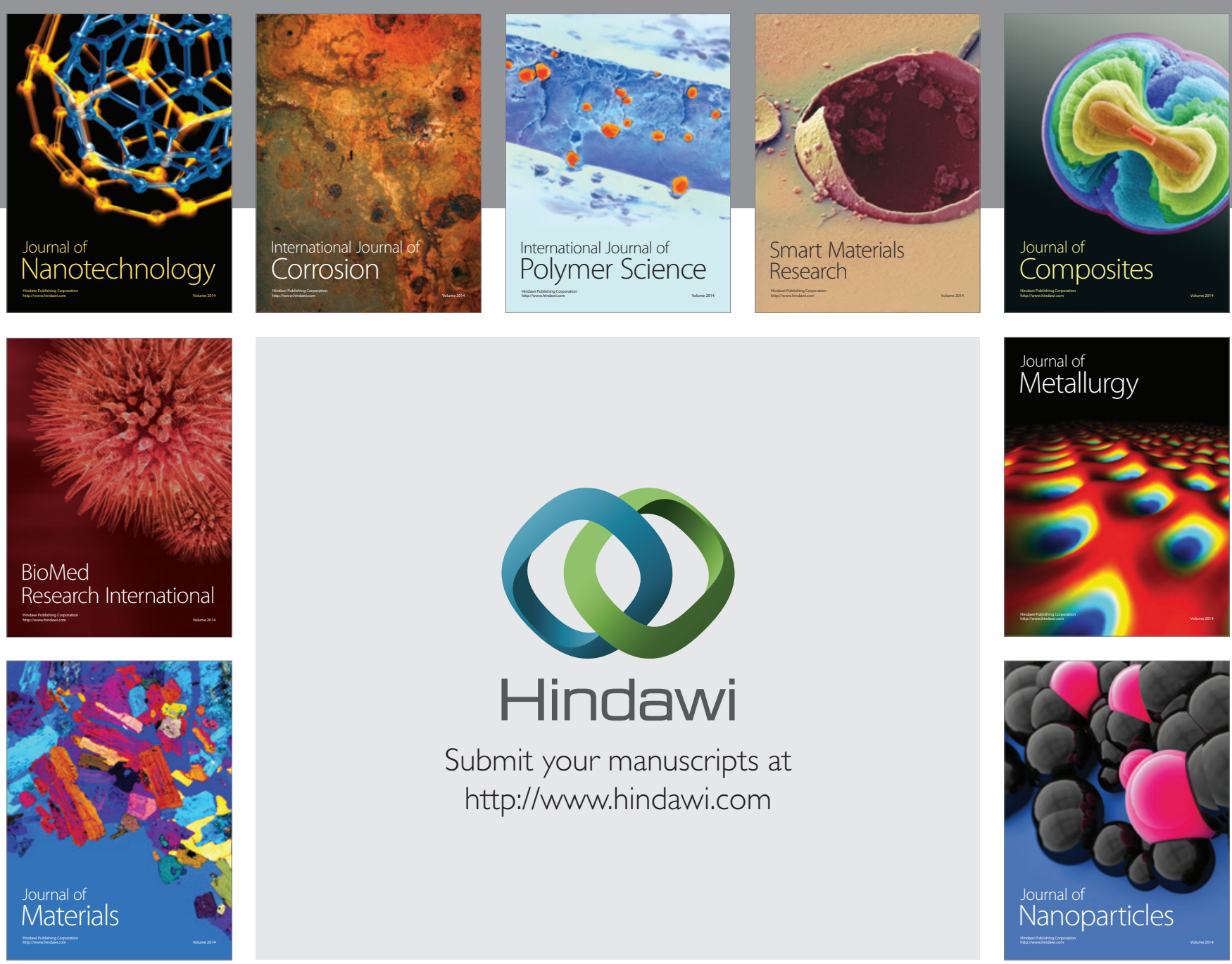

Submit your manuscripts at http://www.hindawi.com
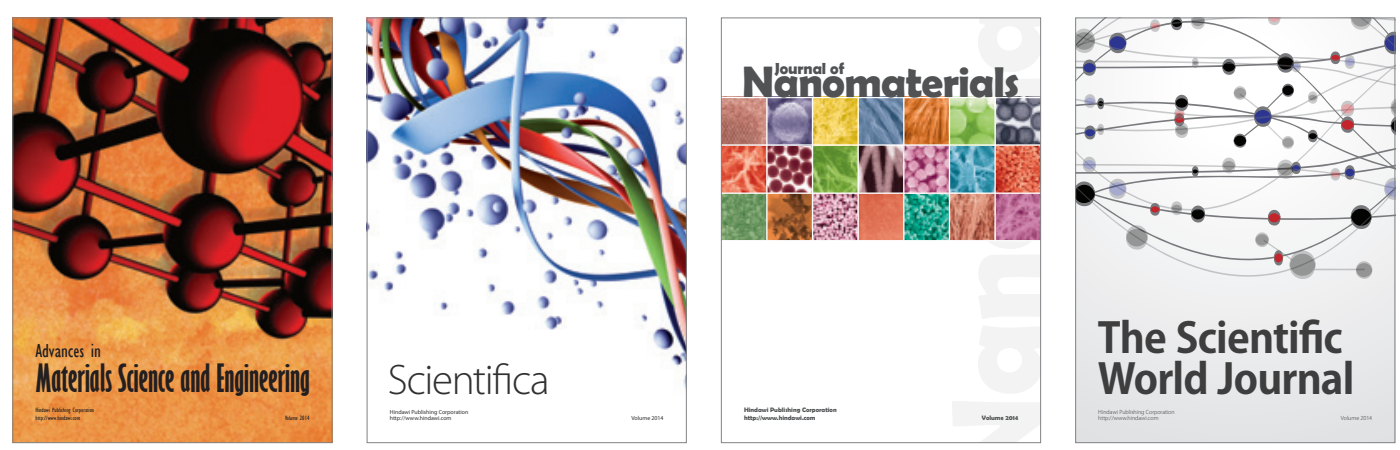

\section{The Scientific World Journal}
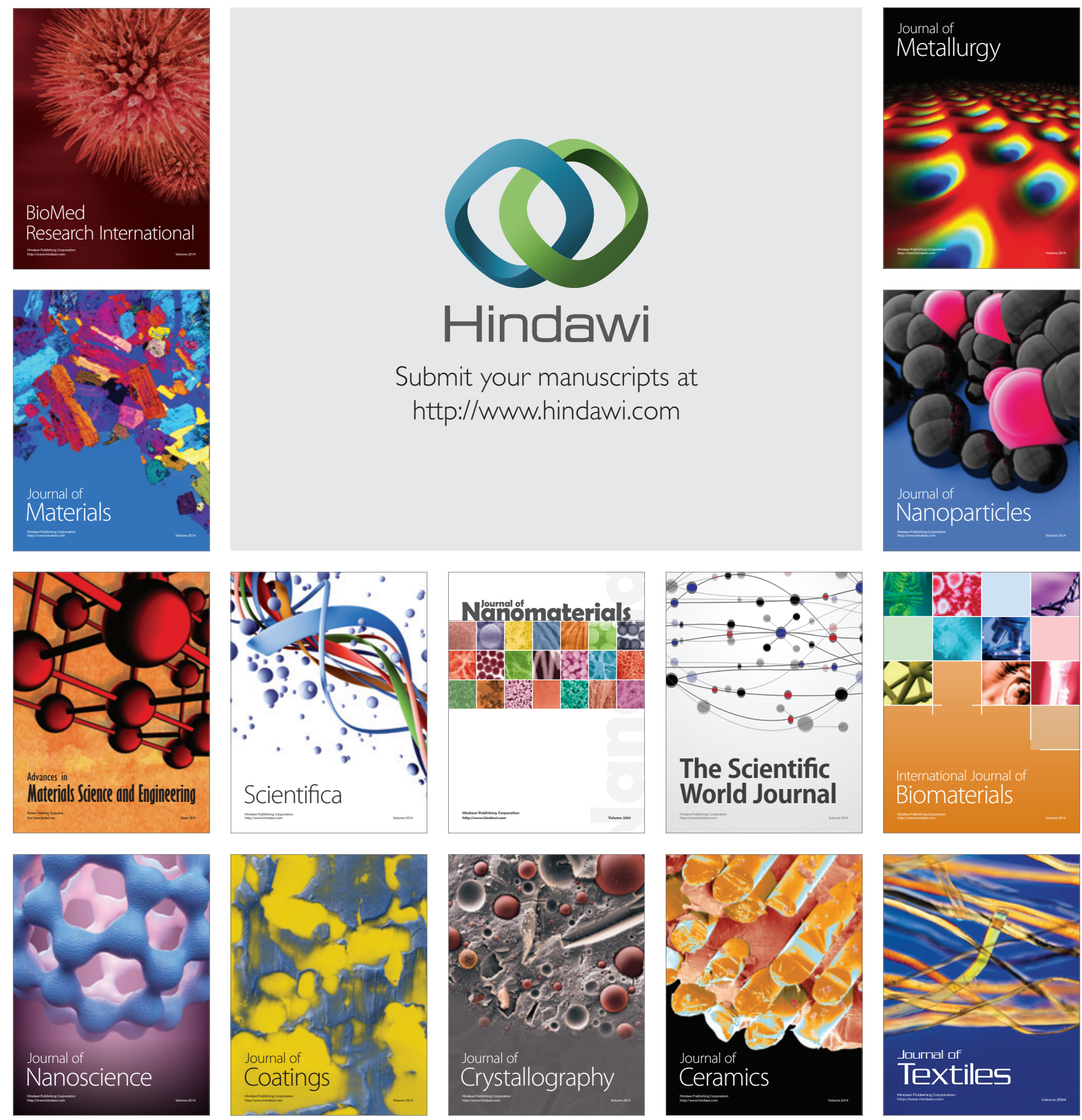